\title{
Differentiated pricing of delivery services in the e-commerce sector
}

Claire Borsenberger, Helmuth Cremer, Philippe De Donder and Denis Joram

April 2015 


\section{Introduction}

Pricing strategies for parcels delivery from e-commerce remain a hot topic for postal and parcel delivery operators. As shown by Borsenberger (2015), the e-commerce sector is subject to concentration trends, due to a fierce price competition between e-retailers, the existence of increasing returns to scale in e-commerce activity, the importance of e-retailers' reputation to attract consumers.

This phenomenon is reinforced by the development of 'marketplaces', which represent virtual intermediate platforms between e-retailers and e-consumers. Marketplaces have developed a win-win intermediation model. Consumers enjoy a greater variety of products (long-tail) and affiliated merchants take advantage of the marketplace's ability to generate huge online traffic and to provide a powerful showcase. ${ }^{1}$ Affiliation to a marketplace presents also some drawbacks for e-retailers. These include fierce price competition leading to reduced margins, the dilution of their own identity and brand to the benefit of the marketplace and in a worst case scenario the creation of a relation of dependence.

The concentration phenomenon raises specific concerns for parcel delivery operators, as input providers for e-retailers. Big e-retailers could have substantial power to negotiate attractive commercial terms for the provision of parcel delivery services in a market characterized by fixed costs and returns to scale. Specifically, this may lead to volume-discount pricing schemes.

This trend is exacerbated by the fact that the major marketplaces provide delivery services to their affiliated merchants. ${ }^{2}$ They become a sort of parcel aggregators, maximizing the volume of parcels provided to delivery operators, in order to increase their quantity discounts.

To put further pressure on parcel delivery operators, big e-retailers like Amazon are developing their own delivery network in dense areas, threatening to bypass traditional delivery operators.

\footnotetext{
${ }^{1}$ The activity of marketplaces is growing in all countries where e-commerce is well-developed. In 2013, 2 million sellers were affiliated to Amazon's marketplace around the world, selling more than 1 billion items. In France, according to Oxatis (2014), 32 percent of e-retailers sold their goods through marketplaces in 2013. According to the FEVAD (2014), the volume of sales realized in marketplaces increased by 42 percent in the last quarter 2013 and represented 16 percent of the global activity of these e-retailers. The five first most visited e-commerce sites in France were marketplaces.

${ }^{2}$ For example, Amazon proposes to its affiliated merchants the service 'Fulfilment by Amazon' (FBA). Merchants pay fees for the various services provided by Amazon: handling the order, picking and packing products, shipping the order (fees depending on the parcel weight and size and the value of order; see Appendix A). Rakuten.com offer a similar storage and shipping service to merchants affiliated to its marketplace: Rakuten Super Logistics (RSL).
} 
In this paper, we examine the link between the delivery rates charged by postal and other parcel delivery operators and the e-commerce market structure. What is the impact of the existence of a marketplace (vs. the presence of independent e-retailers) on the delivery rates and on the economic surplus? Could a delivery operator prevent the development of a marketplace with an appropriate pricing strategy? Which is the best situation from the point of view of the various economic agents (e-retailers, delivery operators, final consumers)?

To answer these questions, we develop a formal model, in Section 2, in which we consider a stylized e-commerce sector with a single parcel delivery operator and two retailers, indexed 0 and 1 . Retailer 0 is a "big” retailer who also operates a marketplace platform, which sells retail and delivery services to other firms.

Initially, we assume that all items are delivered by the postal operator but we also consider the case where operator 0 has a bypass technology, at least in some areas. Retailer 1 can sell independently or via the other firm's marketplace. When it sells independently it uses the delivery services provided by the postal operator and pays the rate it charges. In case of marketplace affiliation it pays a fee to the other retailer who takes care of parcels delivery. Joining the marketplace has other implications. It reduces the degree of product differentiation (so that competition intensity increases) and it increases the willingness to pay for retailer 1's product. This is because the retailers benefit from the reputation of the marketplace.

We study the case where the delivery operator sets the rates charged to each of the two sellers to maximize profits and also look at the Ramsey solution (maximization of welfare subject to a break-even constraint). All variables are evaluated in the induced subgame perfect equilibrium of the price competition game played by the retailers. Depending on the fee charged by the marketplace, operator 1 decides to join or not. In the last stage, the retailers then compete in prices either as independent retailers (Subgame $I$ ) or as marketplace sellers (Subgame $M$ ).

In Section 3, we determine analytically the solution to these games considering as reference scenario the case where all the players maximize their profits and the case where the postal operator maximizes social welfare. While we adopt the simplest possible model which is consistent with the main stylized features of the underlying problem, the analytical solutions are often quite complex. The interpretation is interesting in itself, but to obtain sharper conclusions we resort to numerical simulations in Section 4. Section 5 concludes. 


\section{Model}

Consider an electronic retail market consisting of two sellers (e-retailers) located at 0 and 1 of the Hotelling line. Consumers are distributed over this line, with $z \in[0,1]$. Let $G(z)$ denote the distribution function and $g(z)$ the density. The Hotelling specification is the simplest way to represent horizontal differentiation. In our setting, $z$ is not meant to describe a geographical location but rather a parameter characterizing the individuals’ preferences across retailers.

The retailers sell a single product which apart from their specific retail services is otherwise homogenous. Its marginal cost, excluding delivery is constant and denoted by $k$.

There is a single delivery operator, who charges a rate of $r_{0}$ to retailer 0 . For the time being bypass is ruled out but will be considered below. Seller 1 can either deliver directly via postal operator at rate $r$; the general rate which also applies for single piece senders. Alternatively, it can "join” the marketplace and use the delivery services of retailer 0 . This affects utility and also the degree of product differentiation. We will consider these two market configurations separately.

\subsection{Independent delivery}

In this case referred to as subgame $I$, the utility of consumer $z$, who buys $x$ units of the good is given by

$$
\left\{\begin{array}{cl}
\alpha u(x)-p_{0} x-t z^{2} & \text { if the good is sold by firm } 0 \\
u(x)-p_{1} x-t(1-z)^{2} & \text { if the good is sold by firm } 1
\end{array}\right.
$$

where $\alpha \geq 1$. Firm 0 is a "big" retailer, whose reputation translates into a higher quality perceived by the consumer, which is captured by $\alpha$. Define indirect utility (consumer surplus) as

$$
v(\alpha, q)=\max _{x} \alpha u(x)-q x
$$

The marginal consumer $\hat{z}\left(\alpha, 1, p_{0}, p_{1}\right)$ is defined by

$$
v\left(\alpha, p_{0}\right)-t \hat{z}^{2}=v\left(1, p_{1}\right)-t(1-\hat{z})^{2}
$$

This consumer is indifferent between buying from retailer 0 or 1 . All consumers with a lower value of $z$ will patronize retailer 0 ; they represent a share of $G\left[\hat{z}\left(\alpha, 1, p_{0}, p_{1}\right)\right]$ of the total population. The consumers with $z \geq \hat{z}$, who represent a share of $\left(1-G\left[\hat{z}\left(\alpha, 1, p_{0}, p_{1}\right)\right]\right)$ will buy from seller 1 . Solving for $\hat{z}$ yields 


$$
\hat{z}\left(\alpha, 1, p_{0}, p_{1}\right)=\frac{1}{2}+\frac{v\left(\alpha, p_{0}\right)-v\left(1, p_{1}\right)}{2 t} .
$$

Aggregate (market) demand for the two products is given by

$$
\begin{gathered}
X_{0}^{I}\left(\alpha, 1, p_{0}, p_{1}\right)=x\left(\alpha, p_{0}\right) G\left[\hat{z}\left(\alpha, 1, p_{0}, p_{1}\right)\right], \\
X_{1}^{I}\left(\alpha, 1, p_{0}, p_{1}\right)=x\left(1, p_{1}\right)\left(1-G\left[\hat{z}\left(\alpha, 1, p_{0}, p_{1}\right)\right]\right) .
\end{gathered}
$$

Profits of the e-retailers are given by

$$
\begin{aligned}
& \pi_{0}^{I}\left(\alpha, 1, p_{0}, p_{1}\right)=\left(p_{0}-k-r_{0}\right) X_{0}^{I}\left(\alpha, 1, p_{0}, p_{1}\right), \\
& \pi_{1}^{I}\left(\alpha, 1, p_{0}, p_{1}\right)=\left(p_{1}-k-r\right) X_{1}^{I}\left(\alpha, 1, p_{0}, p_{1}\right),
\end{aligned}
$$

The e-retailers simultaneously set their prices and the solution is given by the Nash equilibrium, denoted by the superscript $N I$. The equilibrium prices are then $\left(p_{0}^{N I}, p_{1}^{N I}\right)$, equilibrium demands are

$$
\begin{aligned}
& X_{0}^{N I}=X_{0}^{I}\left(\alpha, 1, p_{0}^{N I}, p_{1}^{N I}\right), \\
& X_{1}^{N I}=X_{1}^{I}\left(\alpha, 1, p_{0}^{N I}, p_{1}^{N I}\right),
\end{aligned}
$$

and equilibrium profits are

$$
\begin{aligned}
& \pi_{0}^{N I}=\pi_{0}^{I}\left(\alpha, 1, p_{0}^{N I}, p_{1}^{N I}\right), \\
& \pi_{1}^{N I}=\pi_{1}^{I}\left(\alpha, 1, p_{0}^{N I}, p_{1}^{N I}\right) .
\end{aligned}
$$

The postal operator's profits are given by

$$
\Pi^{N I}=\left(r_{0}-c\right) X_{0}^{I}\left(\alpha, 1, p_{0}^{N I}, p_{1}^{N I}\right)+(r-c)\left[X_{1}^{I}\left(\alpha, 1, p_{0}^{N I}, p_{1}^{N I}\right)+Y(r)\right]-F
$$

where $F$ denotes the operator's fixed cost and where $Y(r)$ is the demand for single piece delivery services (by household and other small firms). Formally we have

$$
Y(r)=\operatorname{argmax}[S(Y)-r Y],
$$

where $S(Y)$ is the (aggregate) gross surplus of single-piece customers (other than e-retailers).

\subsection{Marketplace delivery}

In this case, referred to as subgame $M$, the utility of consumer $z$, who buys $x$ units of the good is given by

$$
\left\{\begin{array}{cc}
\alpha u(x)-p_{0} x-\delta \mathrm{tz}^{2} & \text { if the good is sold by firm } 0 \\
\gamma u(x)-p_{1} x-\delta t(1-z)^{2} & \text { if the good is sold by firm } 1
\end{array}\right.
$$

where $\alpha \geq 1,1 \leq \gamma \leq \alpha$ and $\delta<1$. The parameter $\delta$ represents the property that delivery 
through the marketplace reduces the degree of horizontal product differentiation. It reduces the utility loss customers experience when patronizing a seller whose characteristics differ from their preferred ones. Consequently the goods become closer substitutes and price competition will be more intense. When $\gamma>1$, marketplace delivery also increases the perceived quality of good 1; the seller now benefits from the reputation and warranties of the marketplace.

Proceeding as above, the marginal consumer is now determined by

$$
\tilde{z}\left(\alpha, \gamma, p_{0}, p_{1}\right)=\frac{1}{2}+\frac{v\left(\alpha, p_{0}\right)-v\left(\gamma, p_{1}\right)}{2 \delta t},
$$

and aggregate (market) demand for the two products is

$$
\begin{gathered}
X_{0}^{M}\left(\alpha, \gamma, p_{0}, p_{1}\right)=x\left(\alpha, p_{0}\right) G\left[\tilde{z}\left(\alpha, \gamma, p_{0}, p_{1}\right)\right], \\
X_{1}^{M}\left(\alpha, \gamma, p_{0}, p_{1}\right)=x\left(\gamma, p_{1}\right)\left(1-G\left[\tilde{z}\left(\alpha, \gamma, p_{0}, p_{1}\right)\right]\right) .
\end{gathered}
$$

Profits of the e-retailers are given by

$$
\begin{gathered}
\pi_{0}^{M}\left(\alpha, \gamma, p_{0}, p_{1}\right)=\left(p_{0}-k-r_{0}\right) X_{0}^{M}\left(\alpha, \gamma, p_{0}, p_{1}\right)+\left(s-r_{0}\right) X_{1}^{M}\left(\alpha, \gamma, p_{0}, p_{1}\right), \\
\pi_{1}^{M}\left(\alpha, \gamma, p_{0}, p_{1}\right)=\left(p_{1}-k-s\right) X_{1}^{M}\left(\alpha, \gamma, p_{0}, p_{1}\right),
\end{gathered}
$$

where $s$ is the shipping rate retailer 0 charges to retailer 1 .

As in the case of independent delivery we assume that the e-retailers simultaneously set their prices and that the solution is given by the Nash equilibrium, denoted by the superscript $N M$. The equilibrium prices are denoted by $\left(p_{0}^{N M}, p_{1}^{N M}\right)$. Substituting into expressions (14)-(17) yields the equilibrium demands and profit levels, i.e. counterparts to expressions (8)-(11).

Finally, the postal operator's profits under marketplace delivery are given by

$$
\Pi^{N M}=\left(r_{0}-c\right)\left[X_{0}^{M}\left(\alpha, \gamma, p_{0}^{N M}, p_{1}^{N M}\right)+X_{1}^{M}\left(\alpha, \gamma, p_{0}^{N M}, p_{1}^{N M}\right)\right]+(r-c) Y(r)-F .
$$

Comparing equations (12) and (18) shows that the total sales of both retailers are now delivered at the rate $r_{0}$. The marketplace thus introduces a secondary market for delivery services which, even in the absence of bypass, restricts the operator's ability to differentiate prices.

\subsection{Sequence of decision}

The timing of the "full game" consisting of delivery and retail pricing is as follows. In Stage 1 the postal operator sets $r_{0}$ and $r$, to maximize welfare subject to the break-even constraint and anticipating the induced equilibrium. In Stage 2, retailer 0 chooses $s$, that is the rate at which 
it is willing to sell its delivery service to the other retailer. In Stage 3, retailer 1 chooses independent delivery or marketplace delivery. Finally, in Stage 4 the retailers simultaneously choose their prices $p_{0}$ and $p_{1}$ in either the $I$ or $M$ subgame, which are described in Subsections 1 and 2 above.

As usual we solve this game by backward induction to characterize the subgame perfect Nash equilibrium. At each stage the players (operator or retailers) anticipate the impact their choices will have on the equilibrium in the subsequent stages. Though highly stylized, our model is too complicated to provide a full analytical solution. However, some analytical results can be obtained and in any event a thorough examination of the various stages is necessary to properly define the numerical solutions we will calculate in Section 4.

\section{Equilibrium}

We start by studying the last stage of the game. At this point retailer 1 has already decided if it delivers independently or via the marketplace. Consequently, the retailers play subgame $I$ or subgame $M$. We shall examine them separately.

\subsection{Stage 4}

\subsubsection{Subgame $I$}

At this point $r_{0}$ and $r$ are given and $s$ is of no relevance because the retailer has decided not to join the market place. The equilibrium of the price game yields the equilibrium prices, $p_{0}^{N I}\left(r_{0}, r\right), p_{1}^{N I}\left(r_{0}, r\right)$, and profits, $\pi_{0}^{N I}\left(r_{0}, r\right), \pi_{1}^{N I}\left(r_{0}, r\right)$ as functions of the variables set in the earlier stages.

\subsubsection{Subgame $M$}

Once again, $r_{0}, r$ and $s$ are given. The equilibrium of the price game yields $p_{0}^{N M}\left(r_{0}, r, s\right)$, $p_{1}^{N M}\left(r_{0}, r, s\right)$ and the profit levels $\pi_{0}^{N M}\left(r_{0}, r, s\right)$ and $\pi_{1}^{N M}\left(r_{0}, r, s\right)$. Observe that $s$ is now relevant and affects the equilibrium.

Since we study the subgame perfect equilibrium, the comparative statics properties of these functions, in particular with respect to $s$ are relevant to analyze the earlier stages of the game. This is not a trivial exercise because we have to study the equilibrium and not just differentiate the profit functions. However, we can expect that 


$$
\frac{\partial \pi_{1}^{N M}\left(r_{0}, r, s\right)}{\partial s}<0
$$

in words, retailer 1's profit decreases as the delivery fee by the other retailer increases. This is what can be considered the "normal” case which will arise in the numerical examples presented below. The formal analysis which we skip shows, however, that the results are not unambiguous but that it would take strong assumptions to obtain a different result. ${ }^{3}$

Similarly we expect

$$
\frac{\partial \pi_{0}^{N M}\left(r_{0}, r, s\right)}{\partial s}>0
$$

for small levels of $s$ but for some $\hat{s}\left(r_{0}, r\right)$ we may have

$$
\frac{\partial \pi_{0}^{N M}\left(r_{0}, r, s\right)}{\partial s}=0
$$

In words, $\hat{s}$ is the profit-maximizing level of $s$ for retailer 0 .

\subsection{Stage 3}

At this stage, retailer 1 will decide whether or not to join the marketplace. To do so it will compare $\pi_{1}^{N I}\left(r_{0}, r\right)$ and $\pi_{1}^{N M}\left(r_{0}, r, s\right)$. When $\pi_{1}^{N I}\left(r_{0}, r\right)>\pi_{1}^{N M}\left(r_{0}, r, s\right)$, the retailer will choose independent delivery. Otherwise it will join the marketplace.

Note that for this comparison it is not sufficient to compare $r$ and $s$; this is because quality level and degree of product differentiation differ between the two subgames.

Assuming that (19) holds, there exists a critical level of $s, \tilde{s}\left(r_{0}, r\right)$ such that

$$
\pi_{1}^{N I}\left(r_{0}, r\right)=\pi_{1}^{N M}\left(r_{0}, r, \tilde{s}\right) .
$$

For this level of $s$, retailer 1 is indifferent between marketplace and independent delivery. The equilibrium strategy of retailer 1 in the stage is then to choose $I$ if $s>\tilde{s}\left(r_{0}, r\right)$ and $M$ if $s \leq \tilde{s}\left(r_{0}, r\right)$. Note that we have assumed that in case of indifference retailer 1 chooses $M{ }^{4}$

\footnotetext{
${ }^{3}$ The direct effect of $S$ on $\pi_{1}$, even accounting for the induced increase in price is negative by the envelope theorem. However, as $p_{1}$ increases (the best-reply function of retailer 1 shifts upwards) $p_{0}$ will increase (prices are strategic complements) which has a positive effect on retailer1's profit.

${ }^{4}$ This assumption is made for technical reasons. Since one of the possible strategies of retailer 0 may be to set $S=\tilde{S}$ and we may have existence problems if we adopt the opposite assumption.
} 


\subsection{Stage 2}

Retailer 0 , the potential marketplace, sets $s$, the delivery rate charged to the other retailer. This is achieved by comparing $\pi_{0}^{N I}\left(r_{0}, r\right)$ to $\pi_{0}^{N M}\left(r_{0}, r, s^{*}\right)$, where $s^{* M}\left(r_{0}, r\right)$ is the solution to

$$
\begin{aligned}
& \max _{s} \pi_{0}^{N M}\left(r_{0}, r, s\right) \\
& \text { s.t. } s \leq \tilde{s}\left(r_{0}, r\right) .
\end{aligned}
$$

In words, the retailer effectively faces two questions. First, what is the profit maximizing level of $s$ (denoted $s^{* M}$ ) which induces retailer 1 to join the marketplace? Second, how does the profit achieved with $s^{*}$ compare to the profit under independent delivery? While the choice between the two regimes is nominally made by the other retailer it is of course effectively controlled by retailer 0 , through the determination of $s$. Specifically, setting $s>\tilde{s}\left(r_{0}, r\right)$ will induce independent delivery while $s \leq \tilde{s}\left(r_{0}, r\right)$ results in a marketplace equilibrium.

The results obtained for Stages 3 and 4 imply that $s^{*}$ is determined as follows. We have either $s^{* M}\left(r_{0}, r\right)=\min \left[\tilde{s}\left(r_{0}, r\right) \hat{s}\left(r_{0}, r\right)\right]$ when there is an interior solution for the profit maximization in $N M$ or $s^{* M}\left(r_{0}, r\right)=\tilde{s}\left(r_{0}, r\right)$, when there is a corner solution. Operator 0 then sets the highest $s$ for which operator 1 chooses the $M$ subgame.

The optimal level of $s, s^{*}\left(r_{0}, r\right)$ is then given by $s^{* M}\left(r_{0}, r\right)$ when $\pi_{0}^{N M}\left(r_{0}, r, s^{* M}\right) \geq$ $\pi_{0}^{N I}\left(r_{0}, r\right)$ or by some arbitrary level $s^{*}\left(r_{0}, r\right)>\tilde{s}\left(r_{0}, r\right)$ otherwise. We assume that when operator 0 is indifferent between the two regimes, $I$ and $M$, it chooses the one preferred by the postal operator.

\subsection{Stage 0}

We are now in a position to state the problem of the postal operator who sets $\left(r_{0}, r\right)$. As usual we consider a Ramsey problem where the postal operator maximizes welfare subject to a break-even constraint. Recall that this has profit maximization as a special case. ${ }^{5}$

The operator's pricing policy $\left(r_{0}, r\right)$ will induce either the independent delivery or the marketplace equilibrium in the subsequent stages. Writing the objective function in a unified way for both regimes would complicate notation significantly. Consequently we write two separate problems, one for each regime. To determine the best policy one then has to compare

\footnotetext{
${ }^{5}$ Formally the profit maximizing case is obtained by setting the profit target $\bar{\pi}$ at the monopoly level. Observe that in this case the Lagrange multiplier of the break even constraint will tend to infinity.
} 
the level of the objective achieved at these solutions. Analytically this would be difficult but we address this issue in the numerical section.

We now successively consider the postal operator's problem in each of the two regimes. Recall that maximization is over $\left(r_{0}, r\right)$.

\subsubsection{Regime $I$}

The Lagrangean expression associated with the postal operator's problem is given by

$$
\begin{gathered}
L_{I}=\int_{0}^{\hat{z}}\left[v\left(\alpha, p_{0}^{N I}\right)-t z^{2}\right] g(z) d z+\int_{\hat{z}}^{1}\left[v\left(1, p_{1}^{N I}\right)-t(1-z)^{2}\right] g(z) d z+S(Y) \\
+\left(1+\lambda_{I}\right) \Pi^{N I}+\pi_{0}^{N I}\left(r_{0}, r\right)+\pi_{1}^{N I}\left(r_{0}, r\right)-\lambda_{I} \bar{\pi} \\
+\eta_{I}\left[\pi_{0}^{N I}\left(r_{0}, r\right)-\pi_{0}^{N M}\left(r_{0}, r, s^{* M}\right)\right] .
\end{gathered}
$$

Observe that the arguments of the functions $p_{0}^{N I}, p_{1}^{N I}, X_{0}, X_{1}, Y$ and $s^{* M}$ have been dropped for simplicity. All these expressions are directly or indirectly functions of $\left(r_{0}, r\right)$ and are determined in the subsequent stages, as shown in the previous subsections and by taking into account expressions (8)-(9).

The condition associated with $\eta_{I}$, namely

$$
\pi_{0}^{N I}\left(r_{0}, r\right)-\pi_{0}^{N M}\left(r_{0}, r, s^{* M}\right) \geq 0,
$$

is a Kuhn-Tucker constraint (it may or may not be binding), which ensures that the vector of rates $\left(r_{0}, r\right)$ induce an equilibrium of type $I$ in the subsequent stages.

\subsubsection{Regime $M$}

The Lagrangean expression associated with the postal operator's problem is now given by

$$
\begin{gathered}
L_{M}=\int_{0}^{\tilde{z}}\left[v\left(\alpha, p_{0}^{N M}\right)-\delta z^{2}\right] g(z) d z+\int_{\tilde{z}}^{1}\left[v\left(\gamma, p_{1}^{N M}\right)-\delta t(1-z)^{2}\right] g(z) d z+S(Y) \\
+\left(1+\lambda_{M}\right) \Pi^{N M}+\pi_{0}^{N M}\left(r_{0}, r, s^{* M}\right)+\pi_{1}^{N M}\left(r_{0}, r, s^{* M}\right)-\lambda_{M} \bar{\pi} \\
+\eta_{M}\left[\pi_{0}^{N M}\left(r_{0}, r, s^{* M}\right)-\pi_{0}^{N I}\left(r_{0}, r\right)\right] .
\end{gathered}
$$

Once again the arguments of the various functions have been dropped for simplicity. All these expressions are directly or indirectly functions of $\left(r_{0}, r\right)$ and are determined in the subsequent stages, as shown in the previous subsections.

The condition associated with $\eta_{M}$, namely 


$$
\pi_{0}^{N M}\left(r_{0}, r, s^{* M}\right)-\pi_{0}^{N I}\left(r_{0}, r\right) \geq 0,
$$

is a once again Kuhn-Tucker constraint which may or may not be binding. It ensures that the vector of rates $\left(r_{0}, r\right)$ induces an equilibrium of type $M$ in the subsequent stages.

\section{Numerical illustrations}

In this section, we provide numerical simulations whose aim is to illustrate qualitatively the characteristics of the equilibrium obtained with reasonable values of the parameters. A calibration of our model to a specific postal market would require a sizeable amount of empirical work to estimate its various constituents. We leave such a calibration exercise for future research.

We make use of the following values: $k=10, \alpha=1.1, t=25, \gamma=1.05, \delta=0.8$ and $c=0.5$. We assume linear individual demand functions (obtained from quadratic utilities) which are such that (i) their direct price elasticity is 4.2 at a consumer price of 12 , and (ii) that $x(\alpha, 12)=10$. We assume that the distribution of tastes, $G($.$) , is uniform over [0,1]$.

We first describe the equilibrium in the model without bypass, before moving to its sensitivity to various assumptions, and finally to how it is affected by the introduction of bypass by firm 0 .

\subsection{Benchmark results}

As in the previous sections, we solve the game by backward induction, starting with Stage 4. We first present the numerical results obtained in subgame $I$ where firm 1 chooses independent delivery. Table 1 details the first-best allocation, where both $r$ and $r_{0}$ are set equal to their marginal cost, $c=0.5$. The first row of Table 1 corresponds to the situation where firm 1 delivers independently. The first-best retail prices are identical (since they both equal the same marginal cost $k+c=10.5)$ and result in a $(G(\hat{z})=\hat{z}) 81.65 \%$ market share for firm 0 , thanks to its higher quality ( $\alpha=1.1$ ). We assume away fixed costs for the moment, so that all three firms exactly break even, and total welfare is composed exclusively of consumer surplus, denoted by CS. The results presented in Table 1 will help us ascertain the welfare properties of the market equilibrium, to which we now turn. 


\section{Table 1 : First-Best allocation (benchmark)}

\begin{tabular}{|c|c|c|c|c|c|c|c|c|c|c|c|}
\hline Subgame & $r_{0}$ & $p_{0}$ & $p_{1}$ & $\hat{z}$ & $x_{0}$ & $x_{1}$ & $\Pi_{0}$ & $\Pi_{1}$ & $\Pi$ & $C S$ & $C S+\Pi_{0}+\Pi_{1}+\Pi$ \\
\hline I & 0.5 & 10.5 & 10.5 & 0.816463 & 15.25 & 11.575 & 0. & 0. & 0. & 25.732 & 25.732 \\
\hline M & 0.5 & 10.5 & 10.5 & 0.709274 & 15.25 & 13.5 & $3.924 s-1.9624$ & $3.924 s+1.9624$ & 0 & 28.247 & 28.247 \\
\hline
\end{tabular}

Table 2 : Independent delivery equilibrium (benchmark)

$\begin{array}{lllllllllll}r_{0} & p_{0}^{N I} & p_{1}^{N I} & \hat{z} & x_{0}^{N I} & x_{1}^{N I} & \Pi_{0}^{N I} & \Pi_{1}^{N I} & \Pi^{N I} & C S^{N I} & C S^{N I}+\Pi_{0}^{N I}+\Pi_{1}^{N I}+\Pi^{N I} \\ 0.5 & 12.0543 & 11.9741 & 0.684553 & 9.81006 & 5.89984 & 10.4377 & 1.81283 & 0.930544 & 7.90251 & 21.0836 \\ 0.55 & 12.0946 & 11.9807 & 0.677481 & 9.66894 & 5.87428 & 10.1179 & 1.85801 & 1.27481 & 7.62263 & 20.8733 \\ 0.6 & 12.1348 & 11.987 & 0.670494 & 9.52815 & 5.85012 & 9.80527 & 1.90255 & 1.60268 & 7.3504 & 20.6609 \\ 0.65 & 12.1749 & 11.9929 & 0.663597 & 9.3877 & 5.82727 & 9.49986 & 1.94643 & 1.9146 & 7.08569 & 20.4466 \\ 0.7 & 12.215 & 11.9985 & 0.65679 & 9.24758 & 5.80563 & 9.20155 & 1.98963 & 2.21102 & 6.82832 & 20.2305 \\ 0.75 & 12.2549 & 12.0039 & 0.650078 & 9.10782 & 5.78513 & 8.91025 & 2.03216 & 2.49237 & 6.57815 & 20.0129 \\ 0.8 & 12.2947 & 12.0089 & 0.643461 & 8.96842 & 5.7657 & 8.62587 & 2.07401 & 2.7591 & 6.33503 & 19.794 \\ 0.85 & 12.3345 & 12.0137 & 0.636943 & 8.82939 & 5.74726 & 8.34833 & 2.11517 & 3.01163 & 6.09882 & 19.5739 \\ 0.9 & 12.3741 & 12.0182 & 0.630524 & 8.69076 & 5.72977 & 8.07751 & 2.15563 & 3.2504 & 5.86937 & 19.3529 \\ 0.95 & 12.4136 & 12.0226 & 0.624208 & 8.55253 & 5.71316 & 7.81332 & 2.19539 & 3.47583 & 5.64655 & 19.1311 \\ 1 . & 12.4529 & 12.0267 & 0.617995 & 8.41472 & 5.69738 & 7.55564 & 2.23444 & 3.68834 & 5.43022 & 18.9086 \\ 1.05 & 12.4922 & 12.0306 & 0.611887 & 8.27735 & 5.68238 & 7.30439 & 2.27278 & 3.88834 & 5.22025 & 18.6858 \\ 1.1 & 12.5313 & 12.0343 & 0.605886 & 8.14044 & 5.66811 & 7.05944 & 2.31041 & 4.07625 & 5.0165 & 18.4626\end{array}$


Table 3: Marketplaceequilibrium(benchmark)

$\begin{array}{lllllllllllll}r_{0} & s & p_{0}^{N M} & p_{1}^{N M} & \hat{z} & x_{0}^{N M} & x_{1}^{N M} & \Pi_{0}^{N M} & \Pi_{1}^{N M} & \Pi^{N M} & C S^{N M} & C S^{N M}+\Pi_{0}^{N M}+\Pi_{1}^{N M}+\Pi^{N M} \\ 0.5 & 1.6 & 12.23 & 12.5308 & 0.677033 & 9.19507 & 6.05357 & 12.9204 & 1.81989 & 0 . & 7.49796 & 22.2382 \\ 0.6 & 1.59 & 12.2844 & 12.535 & 0.665284 & 9.00471 & 6.03844 & 12.0915 & 1.90994 & 0.801185 & 7.15758 & 21.9602 \\ 0.7 & 1.58 & 12.3384 & 12.5383 & 0.653749 & 8.81567 & 6.02636 & 11.2786 & 1.99955 & 1.56997 & 6.83342 & 21.6816 \\ 0.8 & 1.57 & 12.392 & 12.5408 & 0.642444 & 8.6281 & 6.01709 & 10.481 & 2.08861 & 2.30836 & 6.52513 & 21.4031 \\ 0.9 & 1.57 & 12.4476 & 12.5509 & 0.632095 & 8.43345 & 5.98015 & 9.72386 & 2.15804 & 3.01235 & 6.20087 & 21.0951 \\ 1 & 1.56 & 12.5004 & 12.552 & 0.621257 & 8.24863 & 5.97588 & 8.95625 & 2.24529 & 3.69392 & 5.92224 & 20.8177\end{array}$


Table 2 presents the market equilibrium with independent delivery by firm 1 , as a function of the prices set by the postal operator, $r_{0}$ and $r$. More precisely, we assume from now on that $r$ is set exogenously at 1 . As the reader will see, the results we obtain are already rich and complex, and would be made significantly more complex (especially to report) with the postal operator optimizing on two price dimensions at the same time. As a first pass, we then set $r$ exogenously and concentrate on the ratio between $r_{0}$ and $r$.

Table 2 reports the equilibrium profit-maximizing price levels chosen simultaneously by firms 0 and 1 ( $p_{0}^{N I}$ and $p_{1}^{N I}$ ) and the ensuing allocation as a function of the exogenous value of $r_{0}$ shown in the first column. Comparing with Table 1, we see that firm 0 makes use of its higher quality to raise its price above the one posted by firm 1 , which results in a smaller market share than in Table 1, and in smaller consumer surplus and total welfare. As its input price $r_{0}$ increases, firm 0 increases its retail price and moves further away from the first-best optimal allocation. We also see that prices $p_{0}$ and $p_{1}$ are strategic complements, although $p_{1}$ is much less sensitive to increases in $r_{0}$ than $p_{0}$. An increase in $r_{0}$ benefits firm $1\left(\pi_{1}^{N I}\right.$ increases) at the expense of firm 0 ( $\pi_{0}^{N I}$ decreases) and of both consumer surplus and total welfare. A benevolent social planner would then set a value of $r_{0}$ below cost. The postal operator's profit $\pi^{N I}$ increases with $r_{0}$, even when $r_{0}$ becomes larger than $r$. The intuition for this result is that a profit-maximizing postal operator would like to exploit the larger quality exhibited by firm 0 , and that its only way to extract profit from firm 0 is to increase $r_{0}$.

When the postal firm is maximizing welfare under a break-even constraint, the value of $r_{0}$ it chooses is increasing in its fixed cost $F$. As the postal operator cannot set a value of $r_{0}$ above $r=1$, its profit-maximizing price is $r_{0}=1$. We then see that the maximum value of the fixed cost compatible with breaking-even is 3.688 .

We now turn to the equilibrium with marketplace. The second row of Table 1 shows the first-best allocation in that case. First-best prices are not affected, but the market share of firm 0 decreases to $70.93 \%$ due to the larger quality of the service offered by firm 1 when it uses firm 0 's marketplace. The optimal quantity $x_{1}$, consumer surplus and total welfare are higher than in the first row, while the value taken by $s$ acts only as a transfer between firms 0 and 1 .

The value of $s$ is chosen at stage 2 by firm 0 in order to maximize its profit. We obtain, as surmised in Section 2, that $\pi_{0}^{N M}$ is first increasing and then decreasing in $s$. We also obtain 
that the profit-maximizing value of $s$ is much larger than $r_{0}$ and even than $r$, for all values of $r_{0} \leq r$. The intuition for these results is that firm 0 anticipates that joining its marketplace will result in firm 1's higher quality and thus higher profit, and that $s$ plays the role of an "access charge" to the marketplace. Also, increasing $s$ induces firm 1 to increase its retail price, decreasing the intensity of competition with firm 0 . These two reasons concur in pushing the value of $s$ well above the marginal cost of delivery for firm $0\left(r_{0}\right)$ and even for firm $1(r)$. But firm 0 anticipates that it will realize this profit $\pi_{0}^{N M}$ only if firm 1 accepts to join its marketplace, that is if firm 1's profit with marketplace delivery is at least as large as with independent delivery. We obtain that $\pi_{1}^{N M}$ is decreasing in $s$ (confirming equation (19)) and that this limit pricing constraint is binding for all values of $r_{0}$. In other words, the value of $s$ which equalizes $\pi_{1}^{N I}$ and $\pi_{1}^{N M}$ (denoted as $\tilde{s}\left(r_{0}, 1\right)$ ) is smaller than the value of $s$ which maximizes $\pi_{0}^{N M}$ (denoted as $\left.\hat{s}\left(r_{0}, 1\right)\right)$.

We then report in Table 3 the equilibrium allocation attained in the marketplace for values of $r_{0}$ varying from $c=0.5$ to $r=1 .{ }^{6}$ By comparing Tables 2 and 3 , we see that $\pi_{0}^{N M}>\pi_{0}^{N I}$, for all values of $r_{0}$. Table 3 then depicts the equilibrium allocation as a function of the value of $r_{0}$ chosen by the postal operator in the first stage of the game. We obtain that the postal operator's profit is monotonically increasing in $r_{0}$. A profit-maximizing postal operator will then post $r_{0}=r=1$; in other words it will not give any discount to firm 0 . Both consumer surplus and total welfare are higher with the marketplace than in the subgame with independent delivery by firm 1.

We now turn to the sensitivity analysis of these results.

\subsection{Sensitivity analysis}

We have studied the sensitivity of our results to variations in three assumptions: a larger exogenous value of $r$, a larger impact of joining the platform on the horizontal differentiation between the products offered by both firms (i.e., a lower value of $\delta$ ) and on the quality of good 1 (i.e., a larger value of $\gamma$ ).

A natural question suggested by the numerical results presented in the previous section

\footnotetext{
${ }^{6}$ We vary $s$ by increments of 0.01 in our computations. The value of $s$ reported in Table 3 are the highest for which $\pi_{1}^{N M} \geq \pi_{1}^{N I}$ holds.
} 
is whether setting a higher exogenous value of $r$ (at 2.5 rather than 1) would result in an interior profit-maximizing value of $r_{0}$ for the postal operator (i.e., $r_{0}<r$ ). The answer is positive in the subgame where firm 1 delivers independently, with a profit-maximizing value of $r_{0}$ of 2.35. At the same time, the only role played by $r$ in the subgame with marketplace is to degrade the outside option of firm 1, namely its profit level under independent delivery. The constraint that $\pi_{1}^{N M} \geq \pi_{1}^{N I}$ is then less binding when firm 0 sets its profit-maximizing level of $s$. We even obtain, for low values of $r_{0}$, that this constraint that $\pi_{1}^{N M} \geq \pi_{1}^{N I}$ is not binding at the level of $s$ which maximizes $\pi_{0}^{N M}$ (i.e., $\left.\tilde{s}\left(r_{0}, 2.5\right)>\hat{s}\left(r_{0}, 2.5\right)\right)$. The value of $s$ chosen by firm 1 is then much higher, for any value of $r_{0}$, than in the benchmark numerical results, and firm 0 makes much more profit with the marketplace than with independent distribution by firm 1. Finally, the postal operator's profit remains monotonically increasing with $r_{0}$ as long as $r_{0} \leq r$, and it makes more profit than when $r$ was set at one (so that Ramsey levels of $r_{0}$ are lower, for given $F$, when $r$ is increased to 2.5). Consumer surplus and welfare remain larger at equilibrium (with the marketplace) than in the subgame with independent delivery by firm 1 .

To summarize, a higher exogenous value of $r$ induces an interior profit-maximizing value of $r_{0}$ when firm 1 delivers independently, but not in the equilibrium situation where firm 1 joins the marketplace, because it degrades the outside option of firm 1 and allows firm 0 to set a much higher level of the "access charge" $s$ to its marketplace.

We now go back to the setting where $r=1$, but assume that joining the marketplace decreases the degree of differentiation between products more significantly. Specifically we set $\delta=0.5$ rather than 0.8 . This change does not impact the equilibrium with independent delivery by firm 1, and thus its outside option. Less differentiation in the marketplace results in more intense competition, lower prices and lower profits for both firms for all values of $r_{0}$. We continue to obtain limit pricing by firm 0 (so that $\pi_{1}^{N I}=\pi_{1}^{N M}$ ), but with lower values of $s$ than in the benchmark numerical results. More precisely, as long as $r_{0}$ is low enough, $\pi_{0}^{N M}>\pi_{0}^{N I}$, and firm 0 posts the highest value of $s$ compatible with firm 1 joining the marketplace, $\tilde{s}\left(r_{0}, 1\right)$. When $r_{0}$ is large (although smaller than $r$ ), $\pi_{0}^{N M}<\pi_{0}^{N I}$ when $s=\tilde{s}\left(r_{0}, 1\right)$, and firm 0 posts a high value of $s$ ( larger than $\tilde{s}\left(r_{0}, 1\right)$ ) to deter firm 1 from joining the marketplace. Turning to the postal operator, its profit is increasing in $r_{0}$ as long as firm 1 joins the marketplace, and becomes significantly lower when $r_{0}$ is large enough that the marketplace 
does not form. We then observe some "double limit pricing” when the postal operator maximizes its profit: firm 0 posts the highest value of $s$ compatible with firm 1 joining the marketplace, $\tilde{s}\left(r_{0}, 1\right)$, and the postal operator sets the highest value of $r_{0}$ (strictly lower than $r=1$ ) compatible with firm 0 finding it profitable for firm 1 to join the marketplace $\left(\pi_{0}^{N M} \geq \pi_{0}^{N I}\right)$. Both consumer surplus and aggregate welfare remain higher in the equilibrium with marketplace than in the subgame with independent delivery by firm 1 .

Finally, we assume that joining the marketplace allows firm 1 to bridge most of the quality gap between its product and firm 0's (i.e., we set $\gamma=1.09$ while returning to $r=1$ and $\delta=0.8$ ). This does not affect the equilibrium with independent delivery and the outside option of firm 1 . In the marketplace, firm 0 increases its price $s$ to very high levels up to the point where $\pi_{1}^{N I}=\pi_{1}^{N M}$, and makes much larger profits than with independent delivery by firm 1 . In other words, firm 0 can capture all the increase in firm 1's profit generated by a larger $\gamma$ by increasing the access charge $s$ to the marketplace. The postal operator's profit remains monotonically increasing in $r_{0}$. Interestingly, although total welfare remains higher with the marketplace than in the subgame with independent delivery, consumer surplus is lower: in equilibrium, firm 0 and the postal operator make larger profit, at the expense of consumer surplus, because higher equilibrium prices more than compensate the larger quality offered by firm 1 when it joins the marketplace. Intuitively, this occurs because only consumers who patronize seller 1 benefit from the higher quality, and they represent a small share, whereas all consumers support the price increase of both products.

\subsection{Introduction of bypass}

In this section, we revert to our original parameter values ( $r=1, \delta=0.8$ and $\gamma=1.05$ ) but allow firm 0 to bypass the postal operator and to deliver by itself part or all of its parcels. More precisely, and using the notation introduced in Appendix B, we assume for simplicity that $\beta=1$ and that $d(Q)=Q^{2} / 12$. Table 4 shows the first-best allocation, with its first row devoted to the situation with independent delivery. The only difference with the first row of Table 1 is that firm 0 makes a positive profit of 0.75 , which corresponds to the delivery costs saved by bypassing the postal operator for parts of its volume. More precisely, when $r_{0}=0.5$, firm 0 finds it more economical to deliver by itself 3 units of volumes (since $d^{\prime}\left(Q^{B}\right)=Q^{B} / 6=r_{0}$ is satisfied for $\left.Q^{B}=3\right)$. Consumer surplus is unaffected, compared to the 
first row of Table 1, but total welfare is higher by 0.75 .

Table 5 reports the results obtained in the subgame with independent delivery by firm 1 . We observe that $d^{\prime-1}\left(r_{0}\right)<X_{0}^{N I}$ as long as $r_{0}<0.95$. In that case, the bypass size is affected exclusively by $r_{0}$ (and not by retail prices and volumes), so that we obtain the exact same equilibrium prices and volumes as in Table 2. The only difference with Table 2, for given $r_{0}$, is that $\pi_{0}^{N I}$ is larger (thanks to the lower deliver costs of the bypass technology) while $\pi^{N I}$ is smaller (because of lower volumes delivered by the postal operator). When $r_{0} \geq 0.95$, we have that $d^{\prime-1}\left(r_{0}\right)>X_{0}^{N I}$ so that firm 0 delivers all of its sales, and the equilibrium is not affected by $r_{0}$ anymore. Comparing with the case with no bypass, both equilibrium prices are lower (because firm 0 faces a lower marginal delivery cost, and because prices are strategic complements), firm 0's profit is higher, while the postal operator's and firm 1's profits are both lower. We obtain numerically that the value of $r_{0}$ which maximizes the postal operator's profit is 0.7 . In words, the solution is interior and the price is lower than without bypass. The intuition is that an increase in $r_{0}$ decreases further the volumes delivered by the postal operator, compared to Table 2, because it induces a larger amount of bypass.

Table 6 reports the marketplace equilibrium as a function of $r_{0}$. As long as $r_{0}<0.95$, firm 1 chooses the same value of $s$ as without bypass, namely the value of $s=\tilde{s}\left(r_{0}, 1\right)$ ensuring that $\pi_{1}^{N I}=\pi_{1}^{N M}$. When $r_{0} \geq 0.95, \pi_{1}^{N I}$ is lower than without bypass, which allows firm 0 to post a higher value of $\tilde{s}\left(r_{0}, 1\right)$ in the marketplace equilibrium. In both cases, $\pi_{0}^{N M}>\pi_{0}^{N I}$. The value of $r_{0}$ which maximizes the postal operator's profit is lower than without bypass, and interior at $0.8<r=1$. The intuition for this result is the same as with independent delivery by firm 1 . Note that, for any given $F$ allowing the postal firm to break-even, the Ramsey value of $r_{0}$ is larger than without bypass, because bypass results in lower profits for the postal operator, for any value of $r_{0}$. In a nutshell, bypass results in postal operator's profits which are both lower and more sensitive to the value of $r_{0}$ (because a higher value of $r_{0}$ induces more bypass by firm 0 ). 


\section{Table 4 : First-Best allocation with bypass}

$\begin{array}{lcccccccccccc}\text { Suggame } & r_{0} & p_{0} & p_{1} & \hat{z} & x_{0} & x_{1} & \Pi_{0} & \Pi_{1} & & \Pi & C S & C S+\Pi_{0}+\Pi_{1}+\Pi \\ \text { I } & 0.5 & 10.5 & 10.5 & 0.816463 & 15.25 & 11.575 & 0.75 & 0 . & 0 . & 25.732 & 26.482 \\ \text { M } & 0.5 & 10.5 & 10.5 & 0.709274 & 15.25 & 13.5 & 3.92481 s-1.2124 & 1.9624-3.92481 s & 0 & 28.247 & 28.997 & \end{array}$

\section{Table 5 : Independent delivery equilibrium with bypass}

$\begin{array}{llllllllllllllll}r_{0} & p_{0}^{N I} & p_{1}^{N I} & \hat{z} & x_{0}^{N I} & x_{1}^{N I} & X_{0}^{N I} & d^{\prime-1}\left(r_{0}\right) & X_{1}^{N I} & \Pi_{0}^{N I} & \Pi_{1}^{N I} & \Pi^{N I} & C S^{N I} & C S^{N I}+\Pi_{0}^{N I}+\Pi_{1}^{N I}+\Pi^{N I} \\ 0.5 & 12.0543 & 11.9741 & 0.684553 & 9.81006 & 5.89984 & 6.7155 & 3 . & 1.86109 & 11.1877 & 1.81283 & 0.930544 & 7.90251 & 21.8336 \\ 0.55 & 12.0946 & 11.9807 & 0.677481 & 9.66894 & 5.87428 & 6.55052 & 3.3 & 1.89457 & 11.0254 & 1.85801 & 1.10981 & 7.62263 & 21.6158 \\ 0.6 & 12.1348 & 11.987 & 0.670494 & 9.52815 & 5.85012 & 6.38857 & 3.6 & 1.92765 & 10.8853 & 1.90255 & 1.24268 & 7.3504 & 21.3809 \\ 0.65 & 12.1749 & 11.9929 & 0.663597 & 9.3877 & 5.82727 & 6.22965 & 3.9 & 1.96031 & 10.7674 & 1.94643 & 1.3296 & 7.08569 & 21.1291 \\ 0.7 & 12.215 & 11.9985 & 0.65679 & 9.24758 & 5.80563 & 6.07372 & 4.2 & 1.99255 & 10.6715 & 1.98963 & 1.37102 & 6.82832 & 20.8605 \\ 0.75 & 12.2549 & 12.0039 & 0.650078 & 9.10782 & 5.78513 & 5.92079 & 4.5 & 2.02434 & 10.5977 & 2.03216 & 1.36737 & 6.57815 & 20.5754 \\ 0.8 & 12.2947 & 12.0089 & 0.643461 & 8.96842 & 5.7657 & 5.77083 & 4.8 & 2.05569 & 10.5459 & 2.07401 & 1.3191 & 6.33503 & 20.274 \\ 0.85 & 12.3345 & 12.0137 & 0.636943 & 8.82939 & 5.74726 & 5.62382 & 5.1 & 2.08659 & 10.5158 & 2.11517 & 1.22663 & 6.09882 & 19.9564 \\ 0.9 & 12.3741 & 12.0182 & 0.630524 & 8.69076 & 5.72977 & 5.47974 & 5.4 & 2.11701 & 10.5075 & 2.15563 & 1.0904 & 5.86937 & 19.6229 \\ 0.95 & 12.3812 & 12.019 & 0.629378 & 8.66581 & 5.72672 & 5.45407 & 5.7 & 2.12244 & 10.5083 & 2.16285 & 1.06122 & 5.82872 & 19.5611 \\ 1 . & 12.3812 & 12.019 & 0.629378 & 8.66581 & 5.72672 & 5.45407 & 6 . & 2.12244 & 10.5083 & 2.16285 & 1.06122 & 5.82872 & 19.5611\end{array}$




\section{Table 6 : Marketplace equilibrium with bypass}

\begin{tabular}{|c|c|c|c|c|c|c|c|c|c|c|c|c|c|}
\hline$r_{0}$ & $s$ & $p_{0}^{N M}$ & $p_{1}^{N M}$ & $\hat{z}$ & $x_{0}^{N M}$ & $x_{1}^{N M}$ & $X_{0}^{N M}+X_{1}^{N M}$ & $d^{I^{-1}}\left(r_{0}\right)$ & $\Pi_{0}^{N M}$ & $\Pi_{1}^{N M}$ & $\Pi^{N M}$ & $C S^{N M}$ & $C S^{N M}+\Pi_{0}^{N M}+\Pi_{1}^{N M}+\Pi^{N M}$ \\
\hline 0.5 & 1.6 & 12.23 & 12.5308 & 0.677033 & 9.19507 & 6.05357 & 8.18047 & 3. & 13.6704 & 1.81989 & 0 & 7.49796 & 22.9882 \\
\hline 0.6 & 1.59 & 12.2844 & 12.535 & 0.665284 & 9.00471 & 6.03844 & 8.01185 & 3.6 & 13.1715 & 1.90994 & 0.441185 & 7.15758 & 22.6802 \\
\hline 0.7 & 1.58 & 12.3384 & 12.5383 & 0.653749 & 8.81567 & 6.02636 & 7.84987 & 4.2 & 12.7486 & 1.99955 & 0.729975 & 6.83342 & 22.3116 \\
\hline 0.8 & 1.57 & 12.392 & 12.5408 & 0.642444 & 8.6281 & 6.01709 & 7.69452 & 4.8 & 12.401 & 2.08861 & 0.868356 & 6.52513 & 21.8831 \\
\hline 0.9 & 1.57 & 12.4476 & 12.5509 & 0.632095 & 8.43345 & 5.98015 & 7.53087 & 5.4 & 12.1539 & 2.15804 & 0.852347 & 6.20087 & 21.3651 \\
\hline 1 & 1.6 & 12.5106 & 12.5847 & 0.624002 & 8.21306 & 5.85598 & 7.3268 & 6 & 12.0626 & 2.16822 & 0.663401 & 5.79715 & 20.6914 \\
\hline
\end{tabular}




\section{Conclusion}

This paper has examined the link between the delivery rates charged by parcel delivery operators and the e-commerce market structure. In particular, it has studied the impact of the parcel operators' pricing strategies on the e-retailers' incentives to develop a marketplace. It has considered a market where two e-retailers, a big one, 0 , and a smaller one, 1 sell a homogenous good online.

Initially, all parcels are delivered by a postal operator. However, 0 may or may not offer its competitors the option to join its marketplace through the payment of an access fee. Affiliation to the marketplace has several consequences for 1: (i) it reduces the degree of differentiation between the products, (ii) it increases the perceived quality of 1's product which in turn increases the consumers' willing to pay, and (iii) the marketplace consolidates the parcels send by 0 and 1 and could, in theory obtain better pricing conditions from the postal operator. $^{7}$

Under the assumptions made in the numerical simulations, we obtain that a marketplace will emerge in equilibrium. This is good news for consumers: their surplus increase since the perceived quality of 1's product increases when it uses 0's marketplace services. Compared to the case where 1 remains independent, the welfare is also higher: 0 makes higher profits, 1 is indifferent between both situations, and the postal operator sets the same price in both cases and makes higher profits when there is a marketplace since demand increases.

The fact that the postal operator does not give any discount to 0 even though it is a bigger customer, with the more elastic demand, could appear counterintuitive in an industry characterized by scale economies and where volume discounts are a common practice. A sensitivity analysis shows that the latter result arises because the delivery rate charged to 1 is set at a rather low level. When it is fixed at a higher level, the postal operator concedes a discount to 0 in equilibrium.

Another sensitivity analysis shows that it is not always in the interest of 0 to offer its smaller competitor the possibility to join its marketplace. This is the case for instance if the affiliation to the marketplace reduces significantly the degree of differentiation between e-retailers products and therefore increases competition intensity, resulting in lower prices and lower profits for both firms. The result also emerges when 0's competitive advantage on

\footnotetext{
${ }^{7}$ We have not considered the case where joining the marketplace reduces the perceived quality of the small seller. In that situation 1 might nevertheless find it profitable to join the marketplace, but only if this one offers sufficiently low shipping rates.
} 
delivery pricing (its bargaining power the postal operator) is not sufficiently important; in other words, when the discount offered by the postal operator to 0 is rather small. However, even in this case, it is in the interest of the postal operator to see a marketplace emerge, since this will have a positive impact on the volume of parcels to deliver. Consequently, the postal operator will set a price for parcel delivery such that 0 will find it profitable for 1 to join the marketplace.

Finally, when joining the marketplace has a sufficiently large impact on the perceived quality of 1's product, the emergence of a marketplace it is in the interest of both 0 and the postal operator. But, in this case, although total welfare remains higher with the marketplace than under independent delivery, consumer surplus is lower. As a matter of fact, only consumers who patronize 1 benefit from the higher quality, and they represent a small share, whereas all consumers support the price increase of both products.

In the last section of the paper, we consider the case where 0 is able to bypass the postal operator and deliver by itself part or all of its parcels. In accordance with intuition, the degree of bypass will depend on the rate charged by the postal operator. When it is above a certain threshold, 0 will deliver by itself all its parcels. Face with the threatened, the postal operator will give 0 a higher discount compared to the case where bypass is not available. Not surprisingly, bypass decreases the postal operator’s profits. 


\section{Appendix}

\section{A. Examples of fulfillment fees for orders on Amazon.com}

Note that standard-size shipment, above \$300, ordered on Amazon.com, are eligible for Zero Fee Fulfillment. Under \$300, orders are subjected to fulfillment fees depending on their size and weight.

For a CD (dimensions: 5.6" x 4.9" x 0.4"; unit Weight: 0.2 lb.; outbound Shipping Weight: $1 \mathrm{lb}$.), the Order Handling fee is set at \$0.00, the Pick \& Pack one at $\$ 1.02$ and the Weight Handling fee at $\$ 0.46$. The total fulfillment fee is equal to $\$ 1.48$.

For a book (Dimensions: 8.3" x 5.2" x 1.4"; Unit Weight: 0.4 lb.; Outbound Shipping Weight: $1 \mathrm{lb}$.), these fees are respectively set at $\$ 0.00$, $\$ 1.02$ and $\$ 0.55$, for a total of $\$ 1.57$.

For a mobile device case (Dimensions: 13.8" x 9.0" x 0.7" ; unit Weight: 0.7 lb.; Outbound Shipping Weight: $1 \mathrm{lb}$.), the total fulfillment fee of $\$ 2.48$ is composed of an Order Handling fee of \$1.00 , a Pick \& Pack fee of \$1.02 and a Weight Handling fee of \$0.46.

For a Men’s Top Coat, the Order Handling fee is set at $\$ 0.00$, the Pick \& Pack one at \$4.43, the Weight Handling fee at \$2.51 (total \$6.94).

For a Ping pong table, the total fulfillment fee is set at $\$ 184.01(\$ 0.00+\$ 10.25+$ \$173.76).

\section{B. Introducing bypass}

So far we have assumed that there is no bypass. Assume now that the retailer 0 can deliver by itself an exogenously given share, $\beta \in[0,1]$ of its total volume $Q$ to be delivered, where $Q=X_{0}^{I}$ in case of independent delivery and $Q=X_{0}^{M}+X_{1}^{M}$ in case of marketplace delivery. The delivery cost associated with this bypass technology is given by $d\left(Q^{B}\right)$; we assume $d^{\prime}>0$ and $d^{\prime \prime}>0$. For any given $Q$ firm 0 then chooses $Q^{B}$ and $Q^{P}$ to minimize delivery costs given by

$$
\begin{aligned}
& D_{0}=d\left(Q^{B}\right)+r_{0} Q^{P} \\
& \text { s.t } \\
& Q^{B}+Q^{P}=Q \\
& Q^{B} \leq \beta Q
\end{aligned}
$$

We can have two types of solution: (i) Maximum bypass with $Q^{B}=\beta Q$ which occurs when $d^{\prime}(\beta Q) \leq r_{0}$ or (ii) partial bypass with $Q^{B} \leq \beta Q$, when $d^{\prime}(\beta Q)>r_{0} ; Q^{B}$ is then implicitly 
defined by $d^{\prime}\left(Q^{B}\right)=r_{0}$.

We can then define $Q^{B}\left(r_{0}\right)=\min \left[d^{\prime-1}\left(r_{0}\right), \beta Q\right]$ which represents the solution to this problem.

Bypass does not modify the fundamental structure of the game but some expressions have to be modified. These are given in the following subsection.

\section{B.1 Modified expressions under bypass}

First, retailer 0 's profit has to be rewritten and equations (6) and (16) are replaced by

$$
\pi_{0}^{I}\left(\alpha, 1, p_{0}, p_{1}\right)=\left(p_{0}-k\right) X_{0}^{I}\left(\alpha, 1, p_{0}, p_{1}\right)-r_{0}\left[X_{0}^{I}\left(\alpha, 1, p_{0}, p_{1}\right)-Q^{B I}\right]-d\left(Q^{B I}\right),
$$

where

$$
Q^{B I}=\min \left[d^{\prime-1}\left(r_{0}\right), \beta X_{0}^{I}\left(\alpha, 1, p_{0}, p_{1}\right)\right]
$$

and

$$
\begin{aligned}
\pi_{0}^{M}\left(\alpha, \gamma, p_{0}, p_{1}\right) & =\left(p_{0}-k\right) X_{0}^{M}\left(\alpha, \gamma, p_{0}, p_{1}\right)+s X_{1}^{M}\left(\alpha, \gamma, p_{0}, p_{1}\right) \\
& -r_{0}\left[X_{0}^{M}\left(\alpha, \gamma, p_{0}, p_{1}\right)+X_{1}^{M}\left(\alpha, \gamma, p_{0}, p_{1}\right)-Q^{B M}\right]-d\left(Q^{B M}\right),
\end{aligned}
$$

where

$$
Q^{B M}=\min \left[d^{\prime-1}\left(r_{0}\right), \beta\left(X_{0}^{M}\left(\alpha, \gamma, p_{0}, p_{1}\right)+X_{1}^{M}\left(\alpha, \gamma, p_{0}, p_{1}\right)\right)\right]
$$

Second, the postal operator's profits are redefined as follows:

$$
\Pi^{N I}=\left(r_{0}-c\right)\left[X_{0}^{I}\left(\alpha, 1, p_{0}^{N I}, p_{1}^{N I}\right)-Q^{B I}\right]+(r-c)\left[X_{1}^{I}\left(\alpha, 1, p_{0}^{N I}, p_{1}^{N I}\right)+Y(r)\right]-F
$$

in case of independent delivery and by

$$
\Pi^{N M}=\left(r_{0}-c\right)\left[X_{0}^{M}\left(\alpha, \gamma, p_{0}^{N M}, p_{1}^{N M}\right)+X_{1}^{M}\left(\alpha, \gamma, p_{0}^{N M}, p_{1}^{N M}\right)-Q^{B M}\right]+(r-c) Y(r)-F
$$

in case of marketplace.

Once the profit functions are redefined appropriately, the analysis presented in Section 3 goes through without any modification. 


\section{References}

[1] Borsenberger C. (2015), “The concentration phenomenon in e-commerce”, in M.A. Crew and T.J. Brennan (eds), Postal and Delivery Innovation in the Digital Economy, Edward Elgar, Cheltenham UK, pp. 31-42.

[2] Fevad (2014), “Bilan du e-commerce en France en 2013”, January.

[3] Haucap J. and U. Heimeshoff (2013), “Google, Facebook, Amazon, eBay: Is the internet driving competition or market monopolization?”, DICE Discussion Paper, $n^{\circ} 83$.

[4] Oxatis (2014), “Le profil du e-commerçant en 2014”, January.

[5] Xerfi (2014), “Les marketplaces B2C - Rapport d’analyse concurrentielle et stratégique”, October. 